DOSIER 



\title{
Conjunto de viviendas y espacio público en San Gabriel Alto. Estrategias proyectuales para urbanizar la ladera
}

\author{
Rodrigo Cieza de León / David Ortiz \\ Universidad de Lima, Perú
}

Recibido: 26 de septiembre del 2016 / Aprobado: 22 de diciembre del 2016

El presente artículo describe un proyecto de viviendas y espacio público en Villa María del Triunfo, en Lima, Perú. La descripción del proyecto se realiza sobre la base de cuatro estrategias de diseño que pretenden corresponder acertadamente a la condición de su entorno, de esta manera se intenta aportar a la búsqueda de un modelo proyectual adecuado para las laderas de Lima Metropolitana donde se emplazan asentamientos informales. De manera introductoria, se realizará un cuestionamiento sobre los asentamientos informales, se planteará el valor de un edificio y se resaltará el trabajo de un plan de desarrollo urbano.

Villa María del Triunfo, Lima, Perú, asentamientos informales, ladera, estrategias, diseño, viviendas, espacio público, emplazamiento, modularidad, incrementabilidad, arquitectura, modelo, San Gabriel Alto

\section{Group of Housings and Public Space in San Gabriel Alto. Project} Strategies to Urbanize the Hillside.

This article describes a project of housings and public spaces in Villa María del Triunfo, in Lima, Peru. The description of the project is based on four design strategies that try to fit correctly to its environmental condition, thus it intends to contribute to the search of a project model appropriate for the hillsides of Metropolitan Lima where the informal settlements are. As an introduction, the informal settlements will be questioned, the value of a building will be set out and the work of an urban development plan will be emphasized.

Villa María del Triunfo, Lima, Peru, informal settlements, hillside, strategies, design, housings, public space, site, modularity, incremental, architecture, model, San Gabriel Alto 


\section{INTRODUCCIÓN}

La circunstancia territorial de Lima Metropolitana se ve sometida a la siguiente problemática: los asentamientos informales muestran el mayor crecimiento urbano y demográfico en la ciudad, pero no tienen un nivel de habitabilidad digno.

La mayor parte de la práctica de la arquitectura en Lima Metropolitana se concentra en el sector inmobiliario de inversión privada, así, la ciudad formal es el único territorio en donde un edificio puede emplazarse y donde se desarrolla la mayor parte del saber arquitectónico. Esta vez, pensando en el asentamiento informal, ¿sobre qué estrategias, propias de ese saber, se desarrollarán sus edificios?

$\mathrm{Al}$ pensar en un edificio, se debe tener en cuenta su origen y su consecuencia. Por un lado, el origen se refiere a la indispensable coherencia que debe existir entre el orden espacial y los requerimientos de la sociedad donde se ubica. Es así que, a fin de conservar el orden de su hábitat, deben entenderse las dinámicas de vida ya existentes, que resultan de la ideología que rige una sociedad. La consecuencia, por otro lado, se refiere al impacto formal del edificio en el terreno en el que se emplaza; de esta manera, el orden del hábitat debe de beneficiar su entorno. El producto arquitectónico, entonces, se construirá para satisfacer una necesidad cultural y para beneficiar su entorno (natural o artificial).

En este artículo exploraremos la forma adecuada que debe tener un conjunto habitacional para resolver la problemática del asentamiento informal. Las medidas que el Estado ha tomado frente fenómeno del asentamiento informal no han resuelto su problemática, sino que han servido como un paliativo. No se ha elaborado un proyecto que contemple el contexto social en el que se han generado las migraciones y se han organizado las invasiones. Esto se debe a que se pensó en el inmigrante como la fuerza de trabajo que beneficiaría a estratos socioeconómicos superiores sin tener en cuenta sus necesidades básicas.

Las políticas del Estado destinadas a la vivienda de inmigrantes en los últimos años se limitaban al trazado de lotes y a la fomentación de la inversión privada inmobiliaria. Además, no se tomaba consciencia de la condición geográfica de las laderas de Lima; desde un inicio, los proyectos de vivienda estaban previstos para desarrollarse en terrenos llanos y no en pendientes.

El proyecto de vivienda más relevante a nivel de vivienda social incentivado por el Estado es el de las unidades vecinales (1945-1975), edificios emplazados en terrenos llanos a los que, evidentemente, no les correspondía resolver el crecimiento desordenado en la periferia. Ante esta desatención a la vivienda en ladera, surge el fenómeno de la autoconstrucción, muestra del confort que desea cada persona. Vega Centeno plantea el problema de la autoconstrucción como un problema socio-cultural: "La relación que establece un grupo humano y el espacio que habita, produce fenómenos de cultura" (VegaCenteno, 1992). Esta última idea resulta evidente cuando se reconoce que en un pequeño barrio se comparten costumbres específicas entre sus habitantes (Tokeshi, 2014), lo que finalmente consolida el espacio ocupado y no la búsqueda de un lugar nuevo.

Actualmente el Estado, todavía deficiente, no guía el desarrollo urbano de la ciudad; por el contrario, esta labor la desempeña el capital inmobiliario y comercial. Además, desde inicios del siglo $\mathrm{xx}$ hasta la actualidad, la prioridad por desarrollar proyectos de infraestructura 
pública como complemento indispensable de la vivienda ha sido prácticamente nula.

\section{DESARROLLO}

En los últimos estudios sobre la vivienda informal y específicamente la vivienda en ladera, el Plan Metropolitano de Desarrollo Urbano de Lima y Callao 2035 (PLAM 2035) elabora un instrumento ordenador de los barrios populares: el Proyecto Urbano Integral (PUI). Se desarrollaron, grosso modo, cuarenta proyectos urbanos integrales, constituidos por intervenciones en asentamientos humanos con cinco objetivos principales: lograr la conexión interna y externa (con el resto de la metrópoli), potenciar o crear nuevas centralidades, mitigar las zonas en riesgo, apropiarse de las fronteras en las zonas altas de las laderas y mejorar la habitabilidad mediante el desarrollo de espacios públicos con programas de vivienda social (Labarthe y Rodriguez, 2015).

Para el desarrollo de los PUI, se elaboró un estudio morfológico de laderas y estrategias y posibilidades de ocupación en la periferia (MML, 2014). Entre estas últimas, se desarrolla una de incumbencia para este artículo: "la reubicación temporal en vivienda de remate". Esta estrategia propone construir un conjunto de viviendas de alquiler con tratamiento del espacio público en los lotes vacíos aledaños a la pendiente máxima habitable de una ladera (47\%), que en un inicio fue dispuesta para la construcción de equipamiento público (Gálvez, Muñoz y Rodríguez, 2013).
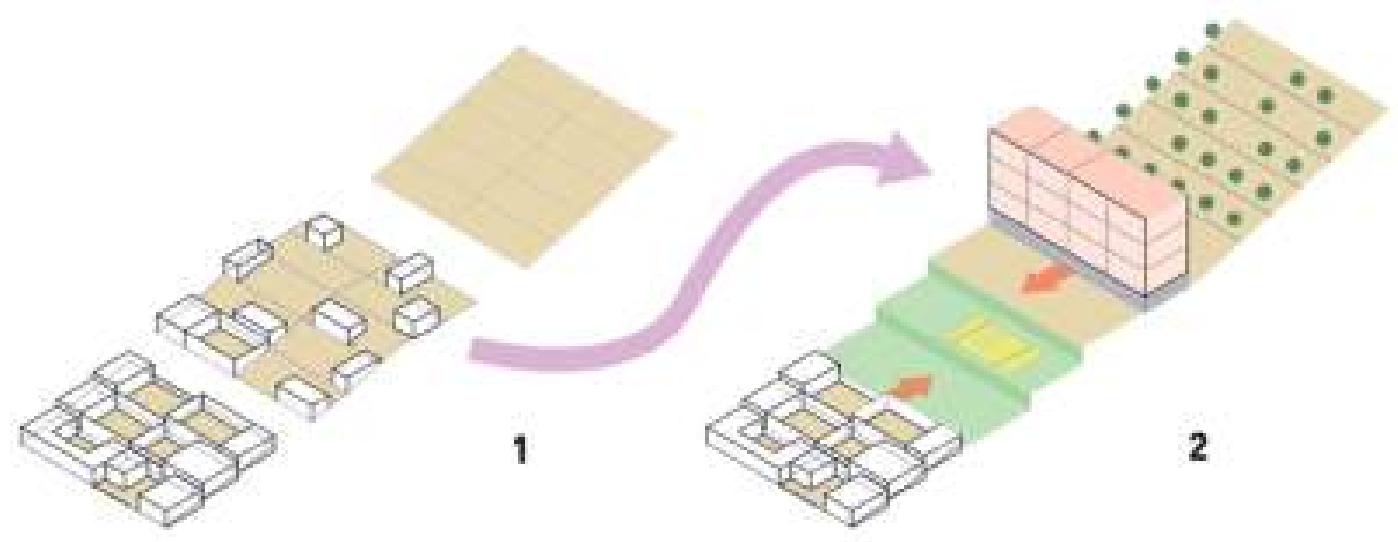

Figura 1

Esquema de reubicación temporal en vivienda de remate (Gálvez, Muñoz y Rodríguez, 2013) 
Considerado los cinco objetivos principales de los PUI y alternando ligeramente la estrategia de ocupación mencionada en el párrafo anterior, hemos desarrollado un proyecto de vivienda y espacio público en el sector San Gabriel Alto ubicado en el distrito de Villa María del Triunfo.

Este proyecto se emplaza en un predio de $11750 \mathrm{~m}^{2}$, en el remate de la importante avenida
San Martín y ocupa parte de dos asentamientos humanos Santa Rosa y La Florida, ubicados en una pendiente no habitable y con, aproximadamente, noventa viviendas registradas (MML, 2014).

Para desarrollar el proyecto sobre la base de lo ya explicado, desarrollamos cuatro estrategias proyectuales que abordan la problemática del asentamiento informal, solucionando su inhabitabilidad.

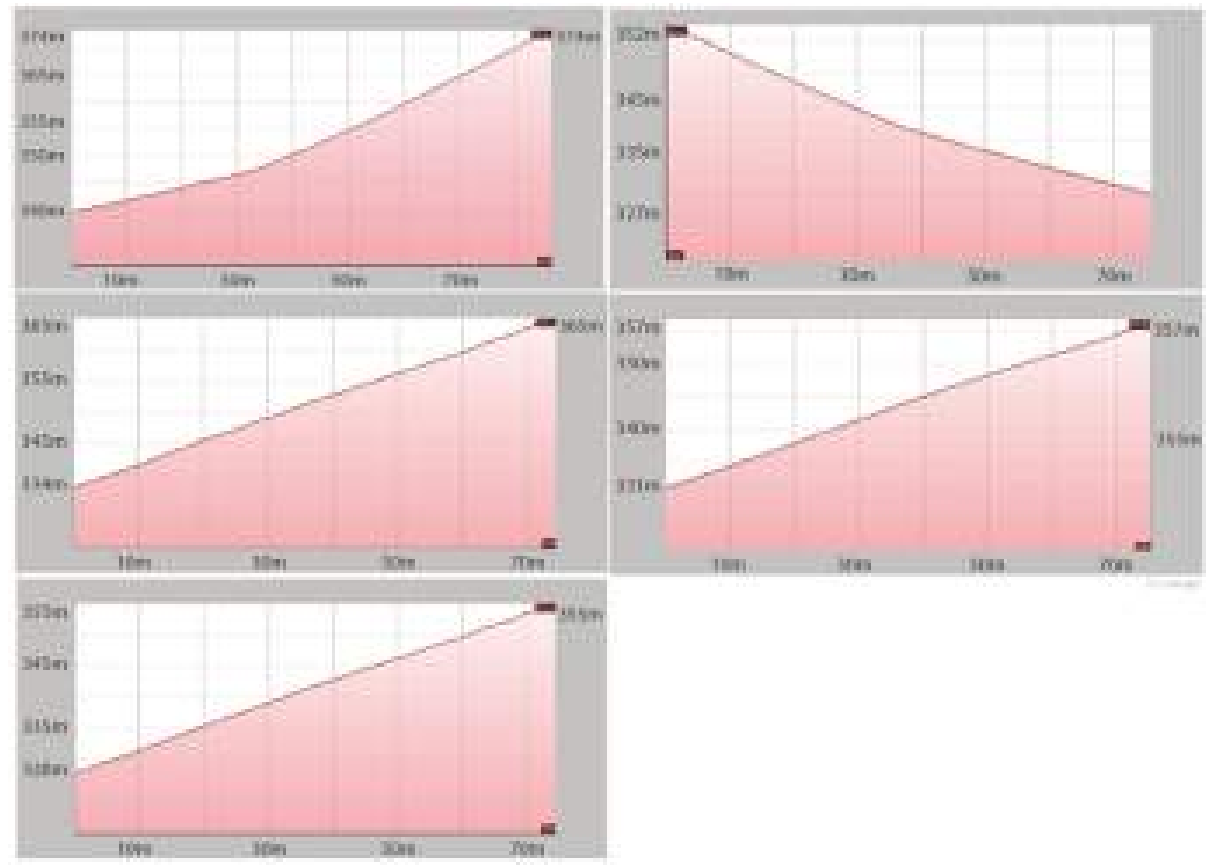

Figura 2

Secciones aproximadas de pendientes en el predio. Revelan un desnivel máximo de $25 \mathrm{~m}$, evidente in situ Imagen obtenida de Google Earth 

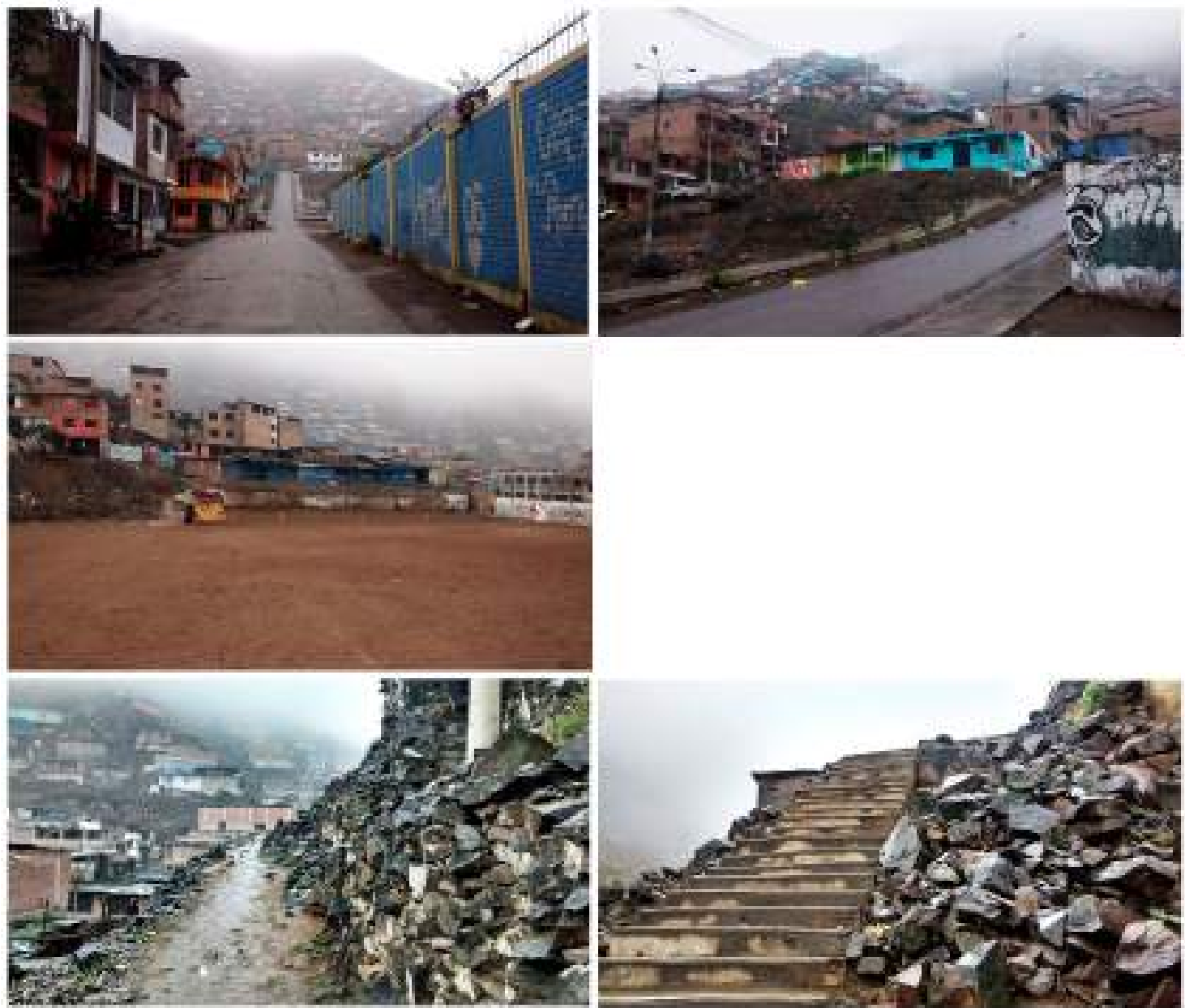

Figura 3

Imágenes del terreno

Fotografías de los autores

\section{EL EMPLAZAMIENTO}

1. Esta estrategia implica un ejercicio muy conocido académicamente, el análisis del entorno, que debe de ser ejecutado in situ. Primero, se deben reconocer las dinámicas de vida existentes para desarrollar un proyecto

coherente con las necesidades de la zona. Este último paso creará consciencia de la forma del espacio público por proyectar, que deberá ser entendido como una nueva topografia que aprovechará al máximo las irregularidades de la anterior. 


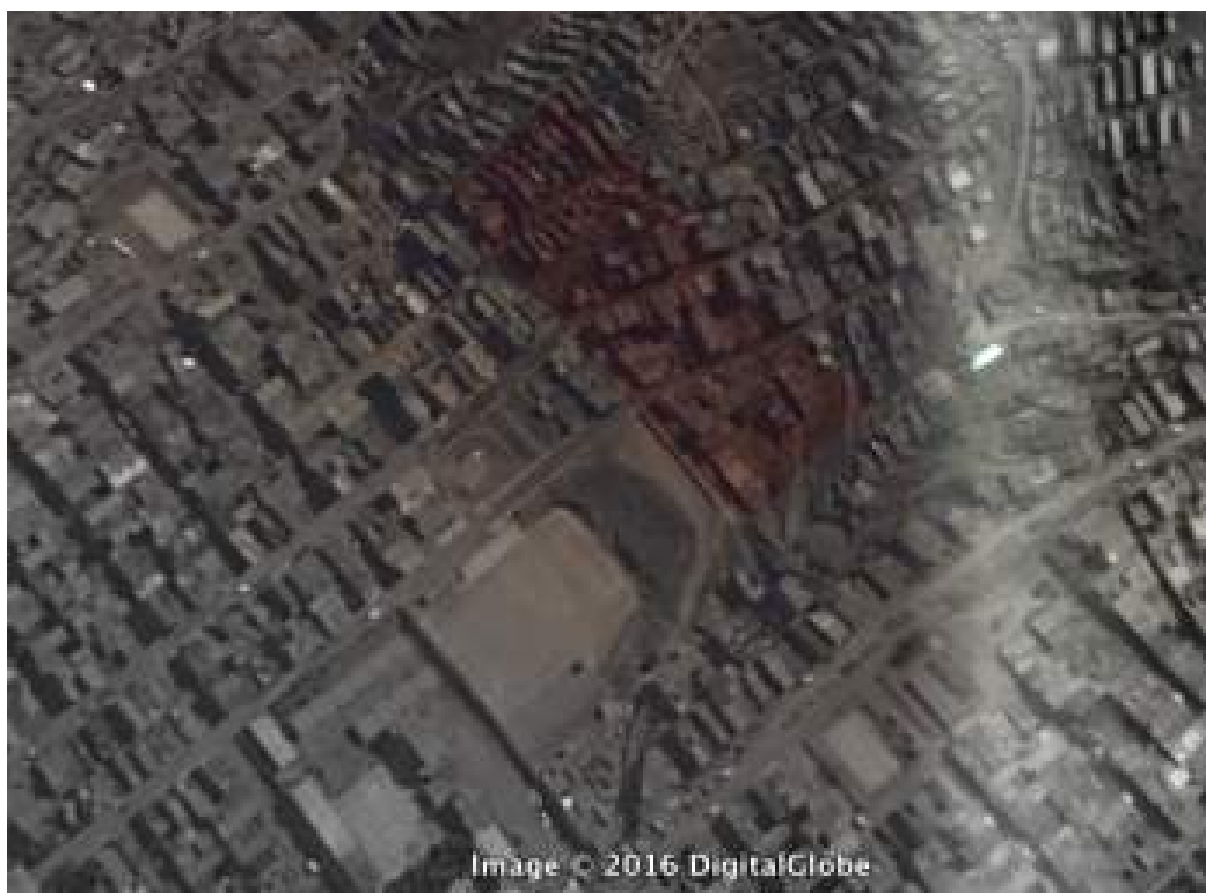

Figura 4

Planta de predio

Imagen obtenida de Google Earth.

2. La forma general de los edificios debe corresponder a su tipología (vivienda) para asegurar iluminación y ventilación natural de los espacios interiores, a fin de garantizar su sanidad. En este proyecto, se proponen cinco volúmenes equidistantes entre sí y resultantes de la división del predio en cuadrantes de $3 \mathrm{~m}$ de arista, que se considera como la mínima dimensión para una habitación confortable en una vivienda.

3. Se debe de corresponder la forma general de los edificios a las dinámicas de vida existentes, reconocidas en el análisis del entorno. En este proyecto, se propone la sustracción de una sección de las tabletas para definir dos espacios públicos: uno próximo al centro del predio, que servirá a manera de remate de la avenida José Carlos Mariátegui y otro en una de las esquinas del predio, que servirá como acceso a un paradero de transporte existente.

4. La forma general de los edificios debe corresponderse con la forma de la ladera reconocida en el análisis del entorno. En este proyecto, se propone la adecuación longitudinal de las tabletas a las curvas de nivel y el desfase vertical para corresponder a las distintas pendientes en distintas partes 
de las tabletas. De esta manera, la forma genérica antes propuesta se torna específica ante su circunstancia.

5. Se formulan las circulaciones. Estas son de dos tipos: rampas y escaleras. Las rampas son las que reconoceremos como circulación orgánica, por lo tanto son paralelas u oblicuas a las curvas de nivel y transversales a la ladera. Las escaleras se definen como la circulación de rápido acceso; en consecuencia, son transversales a las curvas de nivel y paralelas a la ladera.

6. Se da forma a la nueva topografía que sirve a manera de transición entre la base de los edificios y la topografia original. En este proyecto, se proponen plataformas en donde se desarrollarán las actividades de recreación de manera aledaña a las edificaciones de vivienda.
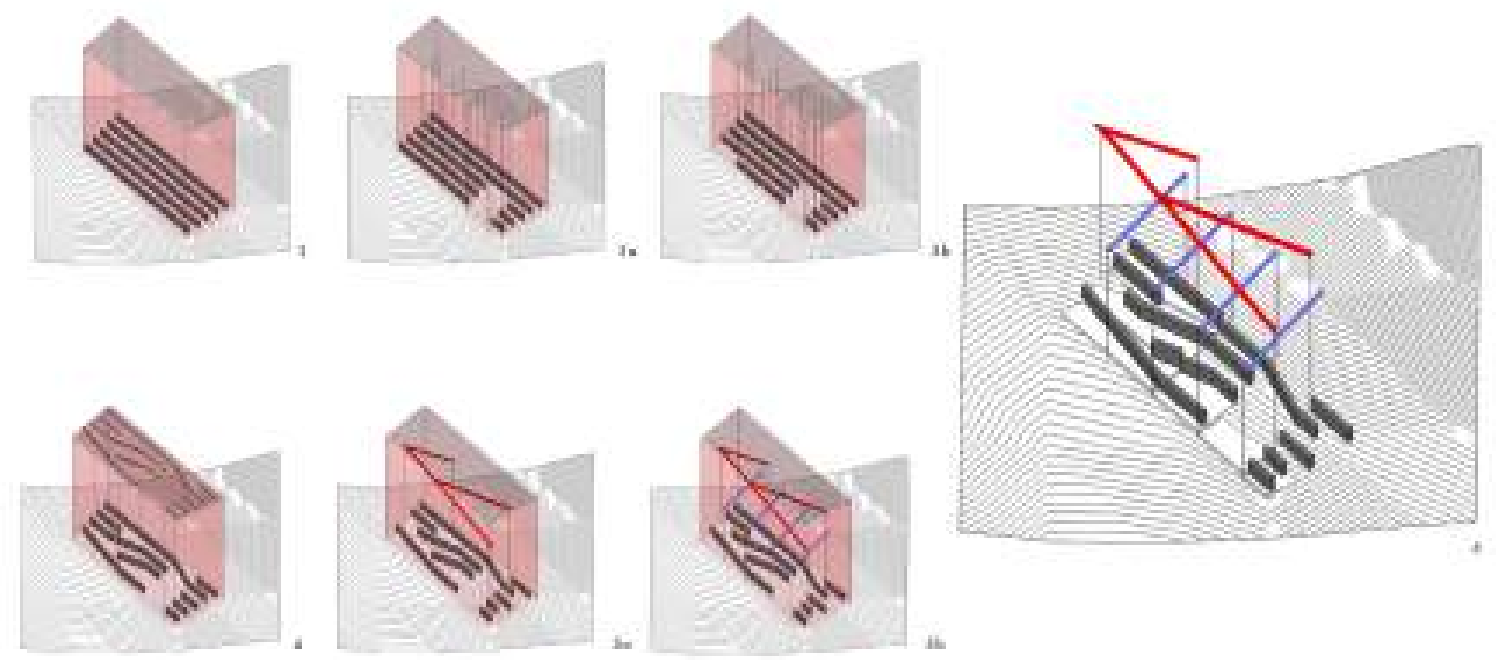

Figura 5

Estrategia de emplazamiento: de forma genérica a forma específica Elaboración propia

\section{ESPACIO PÚBLICO}

Esta estrategia tiene como objetivo principal construir el espacio público como un lugar intangible y vital para el proyecto, que sirva para la recreación y la integración de sus habitantes, a fin de evitar las invasiones. En este proyecto se proponen cinco distintas escalas de espacio público, que varían según su área y aforo.
1. Se propone la construcción de una plaza principal: será la más grande y la de mayor aforo. Su ubicación en el predio la vuelve importante para los vecinos de San Gabriel Alto pues se encuentra en un nivel que la convierte en mirador, además, es el remate de una avenida principal y cercana a una cancha de fútbol abierta. Su forma se puede entender en dos momentos: la circulación orgánica que 
gracias a rampas y descansos amplios, permite que la topografia antigua sea ahora una topografia con actividades de recreación; y la plaza que, gracias a su forma trapezoidal y a su nivel de piso terminado, trasciende los límites del conjunto de viviendas.

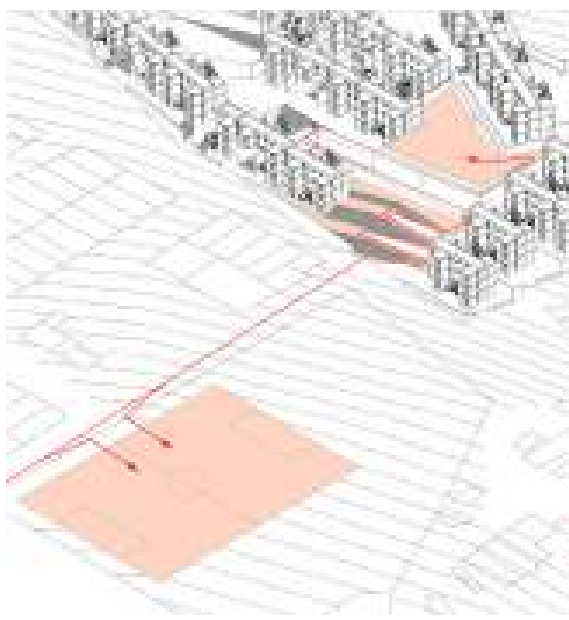

Figura 6

Espacio público: plaza principal

Elaboración propia
2. Se proponen plazas de transición que sirvan a, aproximadamente, cincuenta viviendas cada una. Las plazas se ubican en las transiciones entre la plaza principal y los espacios de uso más doméstico. Su forma es alargada y responde a la adecuación de los edificios a las curvas de nivel. En estos espacios se emplazarán distintos mobiliarios urbanos, como juegos para niños y pérgolas.

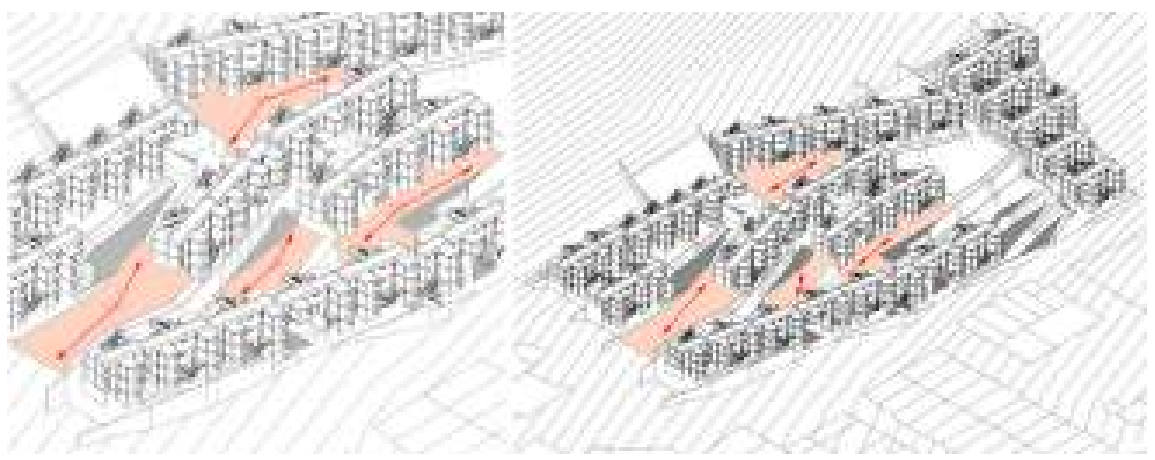

Figura 7

Espacio público: plazas de transición Elaboración propia 
3. Se proponen patios inbetween que sirvan de tres a seis viviendas. Ubicados en los vacíos de la fachada frontal de los edificios de vivienda. Su forma inicial es cuadrada, pero en realidad resulta incierta, pues se ve definida por distintos elementos: el trazado del piso, los parapetos del conjunto, el edificio y su escalera. Este tipo de espacios íntimos pueden comprenderse en un conjunto de viviendas muy estudiado, las del Proyecto Experimental de Vivienda (Previ), y puede decirse que afianzan el nexo entre las viviendas.

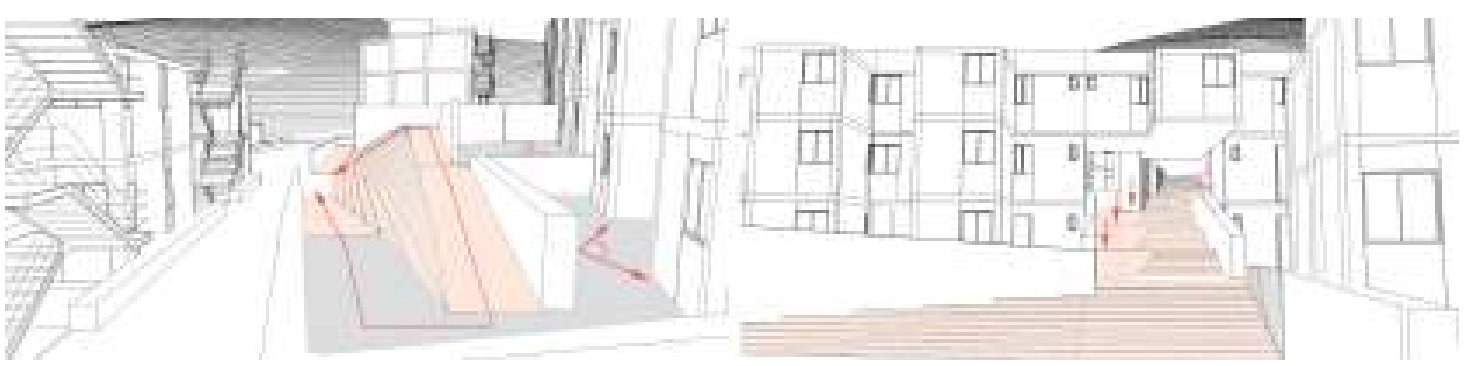

Figura 8

De izquierda a derecha

Espacio público: patios inbetween en gris y circulación orgánica en rojo

Espacio público: circulación de acceso rápido en rojo

Elaboración propia

4. La circulación orgánica y de acceso rápido se proponen como promenade. Se ubican a distintos niveles de la ladera y su forma efectiva es la de los descansos, en donde se forman pequeños espacios de permanencia que aprovechan la altura para servir de mirador.

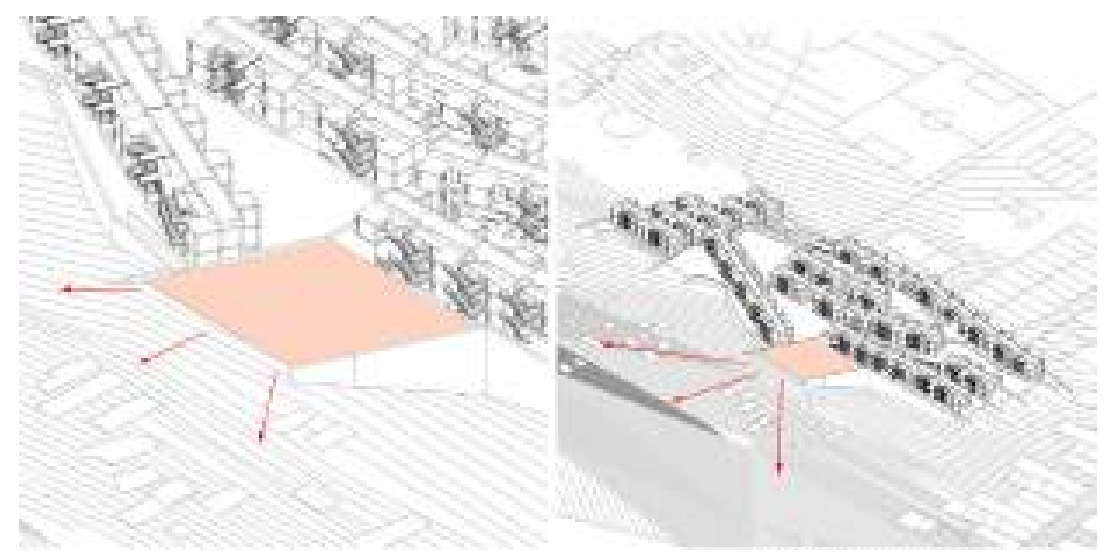

Figura 9

Espacio público: plaza de límite

Elaboración propia 
5. Por último, se propone una plaza de límite. De forma trapezoidal, ubicada en el límite posterior del predio. Su principal función es definir el límite habitable de la pendiente y brindar un nexo coherente al entorno natural. Para este fin, esta plaza deberá ser tratada con un trabajo paisajístico que contemple elementos que no permitan la invasión del área.

\section{MODULARIDAD}

Debido a que es un proyecto de vivienda de bajo costo, la estrategia tiene como fin abaratar los costos del proyecto mediante la producción en masa. La modulación del proyecto se divide en dos partes y estas se subdividen en otras.

1. Se modula el diseño del edificio:

- Se define un espacio confortable que pueda tener distintas funciones; en este proyecto se considera un espacio de $3 \mathrm{~m} \times 3 \mathrm{~m} \times 3 \mathrm{~m}$.

- Se diseña un núcleo húmedo que pueda utilizarse en todas las variaciones de unidades de vivienda y que, entre estas, se ubique uno al costado del otro.

- Se define un sistema de alternancia entre unidades de vivienda y elementos de circulación que genere una experiencia de vida amena. En este proyecto, se elabora un sistema que considera los tres ejes del espacio: en el eje X se ordenan los núcleos húmedos y los dormitorios para generar patios; en el eje Y se ordenan los ambientes para que puedan ser ampliados o divididos; finalmente, en el eje $Z$ se ordenan las circulaciones para que existan dos accesos al edificio en distintos niveles.

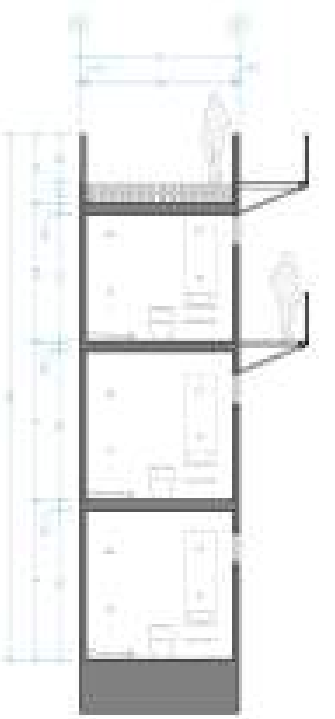



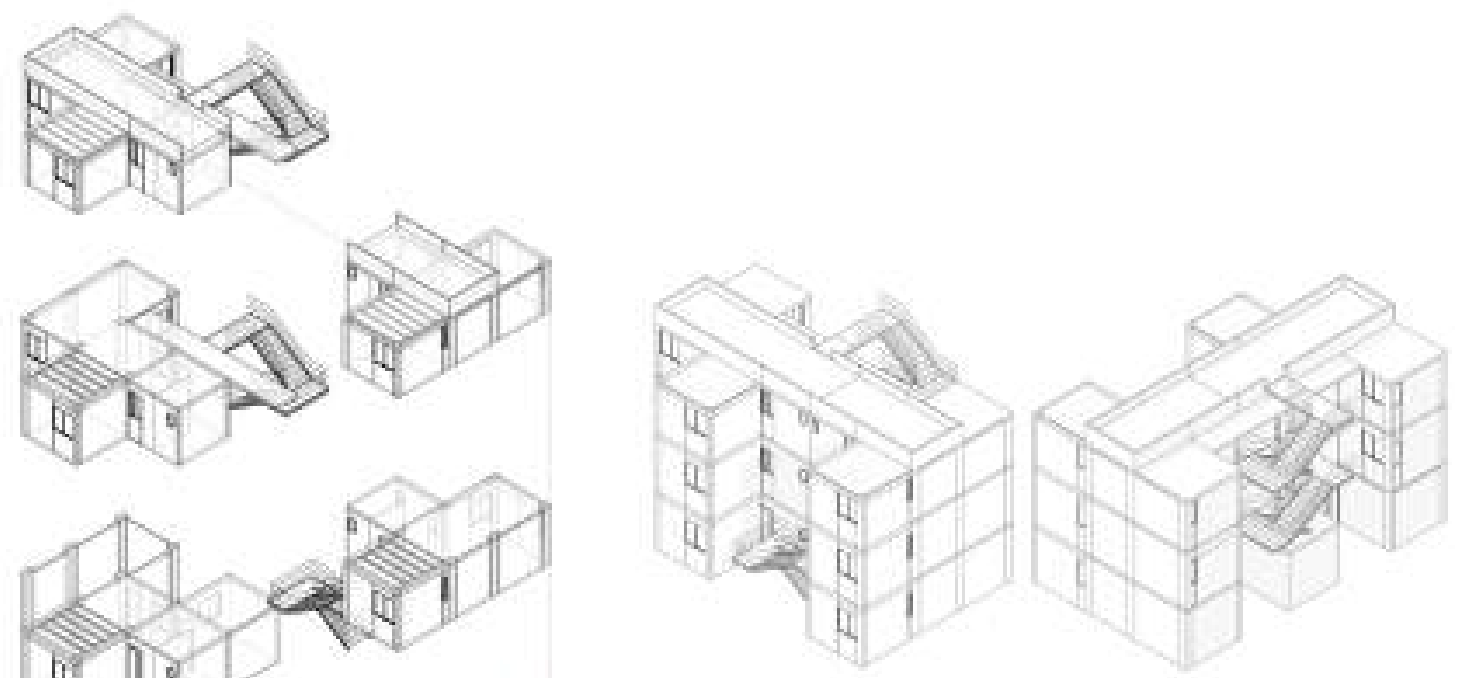

Figura 11

Sistema de alternancia: unidades de vivienda explotadas, fachada frontal y posterior Elaboración propia

2. Se modula el equipamiento del espacio público:

- Para el diseño de los elementos fijos del conjunto se utilizó la menor cantidad de variaciones formales. Se utilizó solo un diseño de rampa para formar la circulación orgánica; asimismo, en la circulación de acceso rápido, se plantea la menor cantidad de variaciones de una escalera tipo. Igual ocurre con los parapetos, que resultan ser la continuación de los muros de contención y en su sección incorporan el drenaje de aguas y un asiento; además, en algunos casos, incorporan una incisión para que crezcan plantas enredaderas.

- En el diseño de los elementos más ligeros, se aplica el mismo método. El proyecto propone zonas de sombra generadas por la repetición de una pérgola construida con bambú y madera reciclada, con una forma que no implique monotonía estética. Lo mismo ocurre con los asientos hexagonales de cemento que, con su repetición, forman jardineras y zonas de juegos para niños. Uno de los dos acabados de piso propuestos es 
un adoquín de cemento hexagonal. En algunas zonas no se coloca ese piso, con la finalidad de permitir el crecimiento de huellas de césped y, en otras, para que crezcan árboles, estratégicamente ubicados, útiles como bloqueadores del sol y del viento.
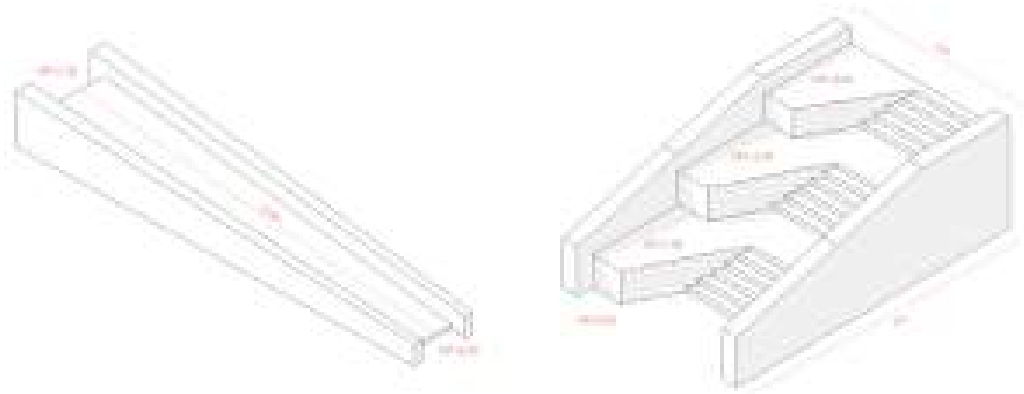

Figura 12

Elementos fijos: rampa, escalera y parapeto

Elaboración propia
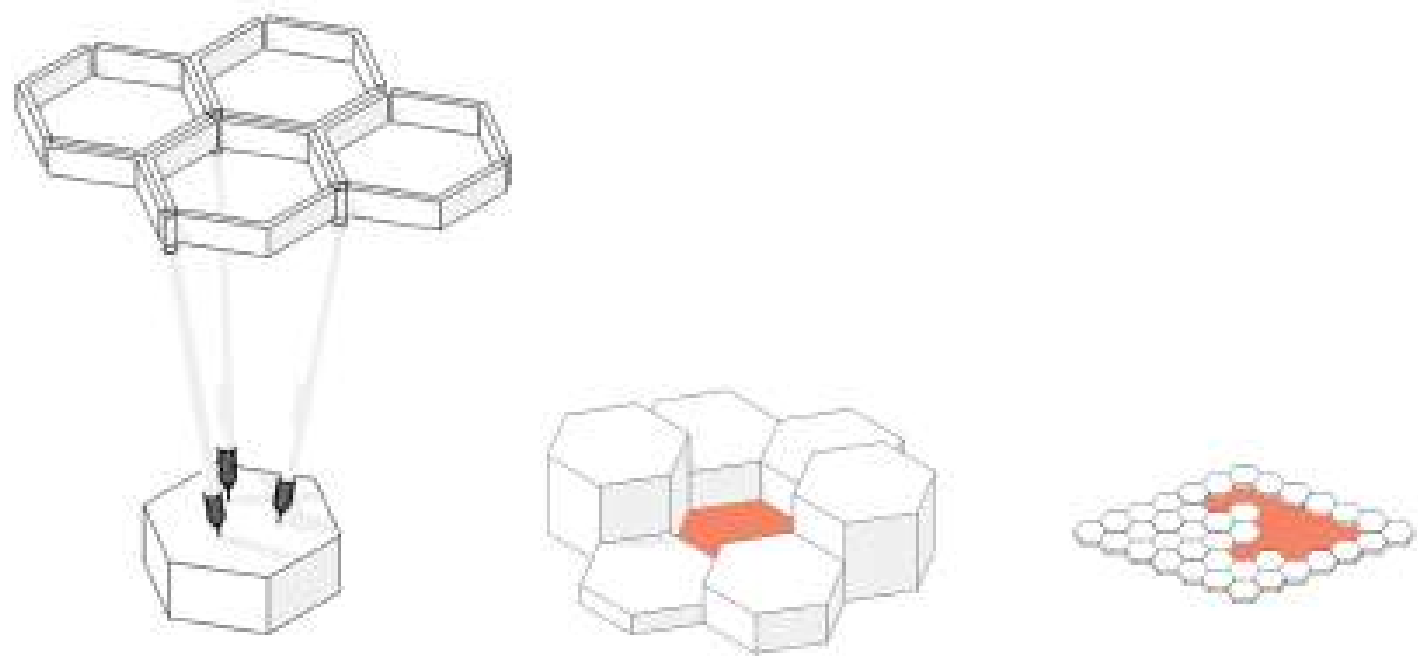

Figura 13

Elementos ligeros: pérgola, asientos y adoquines

Elaboración propia 


\section{INCREMENTO}

Debido a que se trata de un proyecto destinado a familias con un poder adquisitivo en constante desarrollo, esta estrategia tiene como fin generar viviendas con opción a expandirse y reforzar el sentido de pertenencia del habitante hacia su vivienda.

1. El plan de gestión del conjunto contempla como parte del pago mensual de la vivienda las siguientes partes: el pago fraccionado de la vivienda, el mantenimiento del conjunto y el costo de la construcción de la expansión, que resultan ser los módulos de acero de la fachada frontal. Con respecto a la última parte del pago mensual, la construcción de la expansión puede contemplar distintas formas: desde la más básica, solo columnas y losas, hasta la más compleja, que incluye cerramientos, ventanas, acabados de piso y cielo raso.

2. La flexibilidad del diseño permite la posible unión de distintas unidades inmobiliarias para generar una con distintas capacidades, como comercio en el primer o segundo nivel, talleres de trabajo en las viviendas, viviendas más amplias en el eje vertical, entre otras cosas.


Figura 14

De izquierda a derecha: primero, segundo y tercer niveles

Elaboración propia

\section{CONCLUSIÓN}

Con respecto a las necesidades sociales y al entorno construido de Lima Metropolitana, se puede afirmar con toda seguridad que la mayor parte de la sociedad no dispone de los recursos necesarios para configurar un orden adecuado y dar una buena calidad de vida. Sin embargo, han tenido que construir su hábitat y, lamentablemente, el orden resultante no es el adecuado para el desarrollo sostenible de la ciudad.
El fenómeno de migración, invasión, apropiación y autoconstrucción genera el surgimiento del asentamiento informal que lleva a sus habitantes a límites de riesgo: ocupar áreas en las pendientes más pronunciadas de las laderas. Esta realidad es realmente impactante porque implica que en una parte significativa de la sociedad, la necesidad de un hogar es mucho más fuerte que la incomodidad de su emplazamiento conlleva. 
Dicho esto, creímos importante generar un modelo proyectual, una forma de urbanizar adecuadamente las laderas, reconfigurando un asentamiento informal existente en donde los usuarios no gozaban de vivienda y espacio público digno.

Se trabajarán entonces cuatro estrategias que, según el producto arquitectónico obtenido, sirven como pautas para diseñar proyectos emplazados en las laderas de Lima Metropolitana. Gracias a estas estrategias proyectuales se logra definir el límite habitable de la ciudad y se trasciende el nivel de habitabilidad digno, de manera que las dinámicas de vida actualmente existentes se desarrollen en un espacio público con viviendas bellas.

\section{REFERENCIAS}

Gálvez S., Muñoz Unceta, P., y Rodríguez Rivero, L. (2014). Vivienda en laderas en el marco de las zonas de intervención de los PUIs. Recuperado de https://es.scribd.com/ document/256177432/Vivienda-en-Laderas

Labarthe, D., y Rodríguez, L. (2015). Barrio mío. La política urbana como objetivo. Lima: Habitat Universities.

Municipalidad Metropolitana de Lima. (2014). Plan Metropolitano de Desarrollo Urbano de Lima y Callao (PLAM 2035). Lima: MML.

Tokeshi, J. (2014). Cambios socioculturales, vivienda y urbanización el Lima. Construyendo nuestra interculturalidad. Recuperado de http:// interculturalidad.org/numero03/3_04.htm

Vega-Centeno, P. (1992). Autoconstrución y reciprocidad. Cultura y solución de problemas urbanos. Lima: Fomciencias. 